\title{
KAJIAN INTERSEPSI CAHAYA MATAHARI PADA TIGA VARIETAS SORGUM (Sorghum bicolor (L.) Moench) DENGAN KERAPATAN TANAMAN BERBEDA PADA SISTEM TUMPANGSARI DENGAN UBIKAYU (Manihot esculenta Crantz)
}

\author{
Apri Ariyanto, M. Syamsoel Hadi, \& M. Kamal \\ Jurusan Agroteknologi Fakultas Pertanian Universitas Lampung \\ Jl. Prof. Soemantri Brodjoneogoro, No. 1 Bandar Lampung 35145 \\ Email: Apriariyanto@gmail.com
}

\begin{abstract}
ABSTRAK
Tumpangsari tanaman sorgum dengan tanaman ubi kayu merupakan usaha pemanfaatan ruang kosong pada tanaman ubi kayu untuk meningkatkan penggunaan lahan. Persaingan cahaya matahari antartanaman yang ditumpangsarikan merupakan permasalahan dalam sistem ini. Penelitian ini bertujuan untuk mengetahui pola intersepsi cahaya matahari tiga varietas sorgum pada tingkat kerapatan tanaman berbeda pada sistem tumpangsari dengan ubi kayu. Penelitian ini dilaksanakan di Kebun Percobaan Balai Pengkajian Teknologi Pertanian (BPTP) Desa Negara Ratu Kecamatan Natar, Kabupaten Lampung Selatan dari bulan Agustus sampai November 2014. Percobaan disusun secara faktorial (4x3) dalam Rancangan Acak Kelompok Lengkap (RAKL) dengan tiga ulangan. Faktor pertama adalah kerapatan tanaman (p), dan faktor kedua adalah varietas sorgum (g). Hasil penelitian menunjukkan bahwa (1) kerapatan empat tanaman perlubang tanam memiliki persentase intersepsi cahaya matahari tertinggi, (2) intersepsi cahaya matahari ketiga varietas sorgum menunjukkan pola yang relatif sama pada berbagai umur pengamatan (3) interaksi antara varietas dengan kerapatan tanaman memberikan perbedaan intersepsi cahaya matahari tanaman sorgum pada tumpangsari dengan ubi kayu pada umur 5 dan 7 mst dan (4) persentase intersepsi cahaya matahari tanaman sorgum nyata berkorelasi negatif dengan jumlah biji per malai, bobot biji per malai, bobot biji per $\mathrm{m}^{2}$, bobot 100 butir, dan bobot brangkasan kering.
\end{abstract}

Kata kunci: intersepsi cahaya matahari, kerapatan tanaman, tumpangsari, varietas sorgum.

\section{PENDAHULUAN}

Sorgum merupakan salah satu tanaman pangan yang sudah lama dikenal oleh petani Indonesia khususnya di daerah Jawa, NTB dan NTT. Pada setiap daerah tanaman sorgum dikenal dengan nama yang berbedabeda. Di daerah Jawa sorgum dikenal dengan nama Cantel dan umumnya ditanam di lahan tegalan sebagai tanaman sela atau ditumpangsarikan dengan tanaman pangan lainnya (Talanca, 2011). Secara umum, sorgum mempunyai potensi besar untuk dikembangkan di Indonesia karena mempunyai daerah adaptasi yang cukup luas. Tanaman sorgum toleran terhadap kekeringan dan genangan air, dapat berproduksi pada lahan marginal, serta relatif tahan terhadap gangguan hama dan penyakit. Biji sorgum dapat digunakan sebagai bahan pangan, bahan baku industri pakan dan pangan seperti industri gula, monosodium glutamat (MSG), asam amino, dan industri minuman (Sirappa, 2003).

Salah satu usaha intensifikasi pangan adalah dengan dilakukan penanaman ganda atau tumpangsari.
Menurut Warsana (2009), tumpangsari adalah suatu usaha menanam beberapa jenis tanaman pada satu lahan dan waktu yang sama. Penanaman dengan cara ini bisa dilakukan pada dua atau lebih jenis tanaman yang relatif seumur, atau pada beberapa jenis tanaman yang umurnya berbeda. Berdasarkan penelitian Lesoing dan Francis (2000) tumpangsari tanaman sorgum dengan kedelai menunjukan peningkatan hasil tanaman sorgum, namun terjadi penurunan hasil kedelai dibandingkan dengan monokulturnya.

Menurut Hamim dkk. (2012), sistem tumpangsari sorgum dengan tanaman ubikayu merupakan salah satu alternatif yang dapat dilakukan pada lahan yang terbatas. Persaingan unsur hara, air dan cahaya matahari merupakan permasalahan dalam sistem ini. Persaingan yang sangat berpengaruh dalam sistem tumpangsari adalah penyerapan cahaya matahari. Oleh karena itu, untuk menghindari persaingan antar tanaman yang ditumpangsarikan dalam hal mendapatkan sinar matahari, perlu diperhatikan tinggi dan luas antartajuk tanaman yang ditumpangsarikan. Tinggi dan lebar tajuk 
antartanaman yang ditumpangsarikan akan berpengaruh terhadap penerimaan cahaya matahari. Menurut Willey dalam Kantur dkk., (2006), persaingan antara tanaman terhadap cahaya dapat dikurangi dengan mengatur waktu tanam, jarak tanam, kerapatan tanaman, dan defoliasi daun. Efisiensi penggunaan cahaya merupakan komponen penentu pada pertumbuhan dan perkembangan tanaman yang dihubungkan dengan produksi akumulasi biomassa dari intersepsi cahaya (Pembengo dkk., 2012).

Untuk itu dilakukannya penelitian ini dengan tujuan mengetahui pola intersepsi cahaya matahari pada tingkat kerapatan tanaman sorgum berbeda pada sistem tumpangsari dengan ubi kayu, mengetahui pola intersepsi cahaya matahari pada varietas sorgum yang berbeda pada sistem tumpangsari dengan ubi kayu, mengetahui pengaruh interaksi kerapatan tanaman dan varietas sorgum terhadap intersepsi cahaya matahari pada sistem tumpangsari dengan ubi kayu, dan mengetahui korelasi antara persentase intersepsi cahaya matahari dengan hasil sorgum yang ditanam dengan kerapatan berbeda pada sistem tumpangsari dengan ubi kayu.

\section{BAHAN DAN METODE}

Penelitian dilaksanakan di Kebun Percobaan Balai Pengkajian Teknologi Pertanian (BPTP) Desa Negara Ratu Kecamatan Natar, Kabupaten Lampung Selatan dari bulan Agustus sampai November 2014.Percobaan disusun secara faktorial (4×3) dalam Rancangan Acak Kelompok Lengkap (RAKL) dengan tiga ulangan. Faktor pertama adalah kerapatan tanaman (p) yang terdiri dari empat taraf, yaitu satu tanaman per lubang (p1), dua tanaman per lubang (p2), tiga tanaman per lubang (p3), dan empat tanaman per lubang (p4). Faktor kedua adalah varietas sorgum (g) yang terdiri dari 3 taraf, yaitu varietas Numbu (g1), Keller (g2), dan Wray (g3).Data dianalisis dengan analisis ragam dan untuk penentuan perbedaan nilai tengah dilanjutkan dengan uji Beda Nyata Terkecil (BNT) pada taraf $\alpha=5 \%$.

Penanaman antara tanaman ubikayu dan tanaman sorgum dilakukan pada waktu yang bersamaan. Tanaman ubi kayu ditanam dengan jarak tanam $80 \mathrm{~cm}$ x $60 \mathrm{~cm}$, kemudian tanaman sorgum ditanam dengan jarak tanam $80 \mathrm{~cm} \times 20 \mathrm{~cm}$. Tanaman ubikayu yang digunakan adalah varietas Kasetsart.

Pemupukan tanaman sorgum dibagi menadi dua kali. Pemupukan pertama yaitu pupuk Urea, SP-36, dan $\mathrm{KCl}$ dengan perbandingan sebanyak $1 / 3: 1: 1$ bagian diberikan pada umur dua minggu setelah tanam. Pemupukan kedua yaitu pupuk Urea 2/3 bagian (sisa) diberikan pada umur enam minggu setelah tanam.
Kemudian pemupukan tanaman ubikayu digunakan pupuk Urea sebesar $120 \mathrm{Kg} \mathrm{ha}^{-1}$, SP-36 30 sebesar Kg ha $^{-1}$, dan $\mathrm{KCl}$ sebesar $50 \mathrm{Kg} \mathrm{ha}^{-1}$ pada umur 60 hst.

Pengukuran intensitas cahaya matahari pada tanaman sorgum dilakukan dengan menggunakan alat Lux Meter. Pengukuran dilakukan dengan cara mengukur intesitas cahaya matahari di atas dan bawah kanopi tanaman sorgum. Pengamatan dimulai pada umur 4 minggu setelah tanam dengan interval pengamatan setiap 1 minggu. Persentase intersepsi cahaya matahari dapat dihitung dengan rumus:

$$
\mathrm{I}=\frac{\mathrm{a}-\mathrm{b}}{\mathrm{a}}
$$

Keterangan:

I : Persentase intersepsi cahaya matahari $a:$ Jumlah radiasi datang (di atas kanopi)

$b:$ Jumlah radiasi yang ditransmisikan (di bawah kanopi)

Sedangkan pengamatan komponen hasil sorgum dilakukan terhadap jumlah biji per malai, bobot biji per malai, bobot biji per $\mathrm{m}^{2}$, bobot 100 butir biji kering, bobot brangkasan basah, bobot brangkasan kering.

\section{HASIL DAN PEMBAHASAN}

Perbedaan varietas sorgum tidak berpengaruh nyata terhadap intersepsi cahaya matahari tanaman sorgum pada sistem tumpangsari dengan ubikayu, diduga ketiga varietas sorgum memiliki karakteristik yang sama. Karakteristik jumlah daun tanaman sorgum sangat berpengaruh terhadap intersepsi cahaya matahari. Semakin banyak jumlah daun tanaman sorgum, maka akan lebih banyak persentase cahaya matahari yang diintersepsi. Menurut Balai Penelitian Tanaman Serealia (2013), varietas Numbu memiliki jumlah daun sebanyak 14 helai. Tanaman sorgum varietas Keller memiliki jumlah daun sebanyak 9,46 helai, dan varietas Wray memiliki jumlah daun sebanyak 9,56 helai (Rahmawati, 2013).

Kerapatan tanaman berpengaruh nyata terhadap intersepsi cahaya matahari pada umur 4 dan $10 \mathrm{mst}$ (Tabel 1). Hal ini terjadi karena kerapatan tanaman dapat mempengaruhi pertumbuhan dan perkembangan tanaman akibat adanya persaingan akan air, penyerapan cahaya matahari, ruang tumbuh, dan serapan unsur hara pada tanaman sorgum tersebut. Pertumbuhan dan hasil tanaman akan berbeda setiap kerapatan tanaman akibat perbedaan penerimaan cahaya matahari oleh permukaan daun tanaman tersebut (Gardner dkk., 1991). Pada umur 11 dan 13 mst, varietas dan kerapatan tanaman tidak berpengaruh terhadap intersepsi cahaya matahari tanaman sorgum, diduga kanopi tanaman ubikayu sudah 
mulai menaungi tanaman sorgum, sehingga besarnya intersepsi cahaya matahari tanaman sorgum dipengaruhi kanopi tanaman ubikayu.

Kerapatan tanaman satu tanaman per lubang tanam memiliki nilai rata-rata intersepsi cahaya matahari terendah dibandingkan dengan tanaman sorgum yang ditanam dengan kerapatan tanaman dua, tiga dan empat tanaman per lubang (Tabel 1). Semakin tinggi populasi tanaman, maka akan meningkatkan Indeks Luas Daun
(ILD) tanaman tersebut. Suryadi dkk., (2013) menyatakan persentase intersepsi cahaya matahari maksimum terjadi pada kerapatan tanaman tertinggi, cahaya matahari yang datang sebagian besar jatuh pada tajuk tanaman sehingga besarnya intersepsi cahaya dipengaruhi oleh jumlah populasi tanaman atau kerapatan tanaman. Intersepsi cahaya matahari tanaman sorgum secara nyata dipengaruhi interaksi varietas sorgum dan kerapatan tanaman (Tabel 2 dan Tabel 3). Interaksi

Tabel 1. Pengaruh varietas sorgum dan kerapatan tanaman terhadap intersepsi cahaya matahari tanaman sorgum pada 4 dan 10 mst.

\begin{tabular}{|c|c|c|}
\hline \multirow{3}{*}{ Perlakuan } & \multicolumn{2}{|c|}{ Umur Tanaman (mst) } \\
\hline & 4 & 10 \\
\hline & …............ & $\ldots \ldots \ldots \ldots$ \\
\hline \multicolumn{3}{|c|}{ Kerapatan Tanaman } \\
\hline 1 & $32,74 \mathrm{a}$ & $82,01 \mathrm{a}$ \\
\hline 2 & $43,26 \mathrm{~b}$ & $85,79 \mathrm{ab}$ \\
\hline 3 & $47,17 \mathrm{~b}$ & $89,68 \mathrm{~b}$ \\
\hline 4 & $44,40 \mathrm{~b}$ & $90,24 \mathrm{~b}$ \\
\hline BNT 0,05 & 9,06 & 7,66 \\
\hline
\end{tabular}

Keterangan: Angka-angka yang diikuti huruf yang sama dalam setiap kolom dan perlakuan yang sama tidak berbeda nyata berdasarkan uji BNT $5 \%$.

Tabel 2. Pengaruh interaksi varietas sorgum dan kerapatan tanaman terhadap intersepsi cahaya matahari tanaman sorgum pada umur 5 mst.

\begin{tabular}{|c|c|c|c|c|c|}
\hline \multirow[b]{2}{*}{ Varietas } & \multicolumn{4}{|c|}{ Kerapatan tanaman } & \\
\hline & 1 & 2 & 3 & 4 & \\
\hline \multirow{2}{*}{ Numbu } & $33,38 \mathrm{c}$ & $63,08 \mathrm{a}$ & $45,03 \mathrm{~b}$ & $62,24 \mathrm{a}$ & \multirow{6}{*}{8,86} \\
\hline & B & A & $\mathrm{B}$ & $\mathrm{A}$ & \\
\hline \multirow{2}{*}{ Keller } & $43,90 \mathrm{~b}$ & $48,52 \mathrm{ab}$ & 55,96 a & $41,85 \mathrm{~b}$ & \\
\hline & A & $\mathrm{B}$ & A & $\mathrm{B}$ & \\
\hline \multirow{2}{*}{ Wray } & $41,34 \mathrm{bc}$ & $47,12 \mathrm{~b}$ & $36,71 \mathrm{c}$ & 57,82 a & \\
\hline & $\mathrm{A}$ & $\mathrm{B}$ & $\mathrm{C}$ & $\mathrm{A}$ & \\
\hline BNT 0,05 & 7,68 & & & & \\
\hline
\end{tabular}

Keterangan: Angka-angka yang diikuti huruf yang sama (huruf kecil = horizontal, huruf besar = vertikal) tidak berbeda nyata berdasarkan uji BNT $5 \%$. 
Tabel 3. Pengaruh interaksi varietas sorgum dan kerapatan tanaman terhadap intersepsi cahaya matahari tanaman sorgum pada umur 7 mst.

\begin{tabular}{lcccc}
\hline & \multicolumn{5}{c}{ Kerapatan tanaman } \\
\cline { 2 - 5 } Varietas & 1 & 2 & 3 & 4 \\
\cline { 2 - 6 } & $27,72 \mathrm{c}$ & $68,42 \mathrm{a}$ & $59,23 \mathrm{~b}$ & $69,05 \mathrm{a}$ \\
\cline { 2 - 6 } Numbu & $\mathrm{B}$ & $\mathrm{A}$ & $\mathrm{A}$ & $\mathrm{A}$ \\
& $55,10 \mathrm{a}$ & $57,74 \mathrm{a}$ & $59,77 \mathrm{a}$ & $59,45 \mathrm{a}$ \\
Keller & $\mathrm{A}$ & $\mathrm{B}$ & $\mathrm{A}$ & $\mathrm{B}$ \\
& $55,16 \mathrm{ab}$ & $47,52 \mathrm{~b}$ & $59,42 \mathrm{a}$ & $61,07 \mathrm{a}$ \\
Wray & $\mathrm{A}$ & $\mathrm{C}$ & $\mathrm{A}$ & $\mathrm{B}$ \\
\hline BNT 0,05 & 6,88 & & & \\
\hline
\end{tabular}

Keterangan: Angka-angka yang diikuti huruf yang sama (huruf kecil = horizontal, huruf besar = vertikal) tidak berbeda nyata berdasarkan uji BNT $5 \%$.

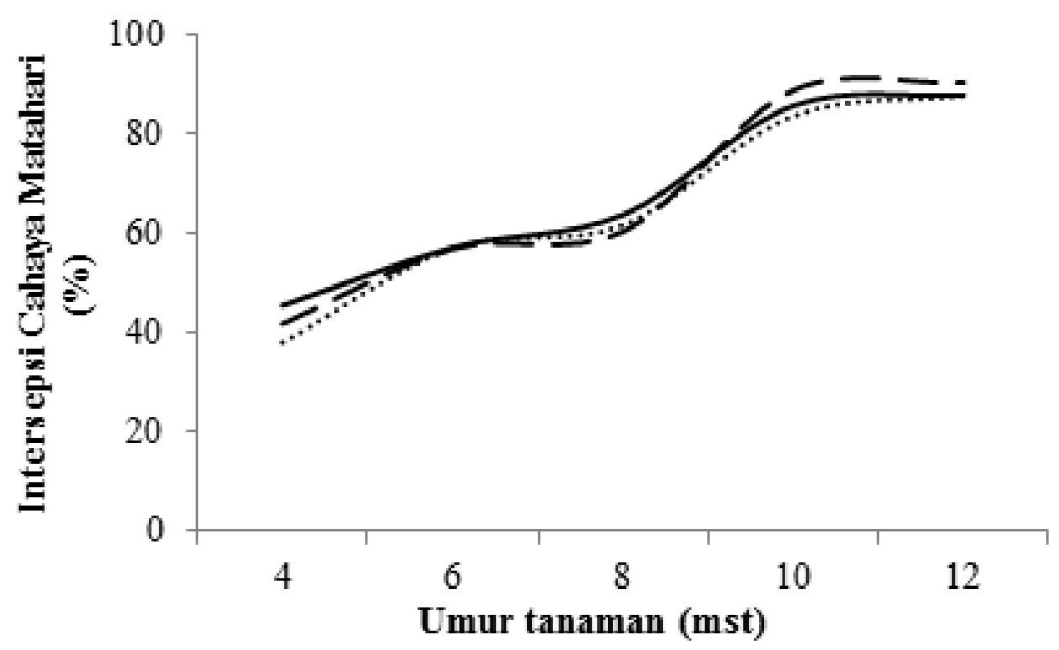

Gambar 1. Pola intersepsi cahaya matahari tiga varietas sorgum. $-=$ Numbu $---=$ Keller; $\ldots . .=$ Wray.

varietas sorgum dan kerapatan tanaman berpengaruh nyata terhadap intersepsi cahaya matahari pada 5 dan 7 mst. Hal ini menunjukkan bahwa keragaan genotipe dipengaruhi oleh lingkungannya. Sesuai dengan pendapat Kuswanto (2007) dalam Sari (2013) bahwa interaksi genotipe dengan lingkungannya akan menghasilkan penampilan fenotipe yang berbeda antar genotipe pada lokasi yang sama.

Intersepsi cahaya matahari pada tiga varietas sorgum memiliki pola yang relatif sama (Gambar 1). Pada berbagai kerapatan tanaman, intersepsi cahaya matahari tanaman sorgum juga menunjukkan pola yang relatif sama (Gambar 2). Namun, tanaman sorgum yang ditanam dengan kerapatan empat tanaman per lubang tanam memiliki persentase intersepsi cahaya matahari tertinggi dan tanaman sorgum yang ditanam dengan kerapatan satu tanaman per lubang tanaman memiliki persentase intersepsi cahaya matahari terendah. Semakin tinggi kerapatan tanaman akan meningkatkan populasi tanaman, sehingga persaingan antar tanaman terhadap cahaya matahari akan lebih tinggi. Tanaman sorgum yang ditanam dengan kerapatan tinggi akan menerima persen cahaya matahari yang lebih rendah dibandingkan dengan tanaman sorgum yang ditanam 


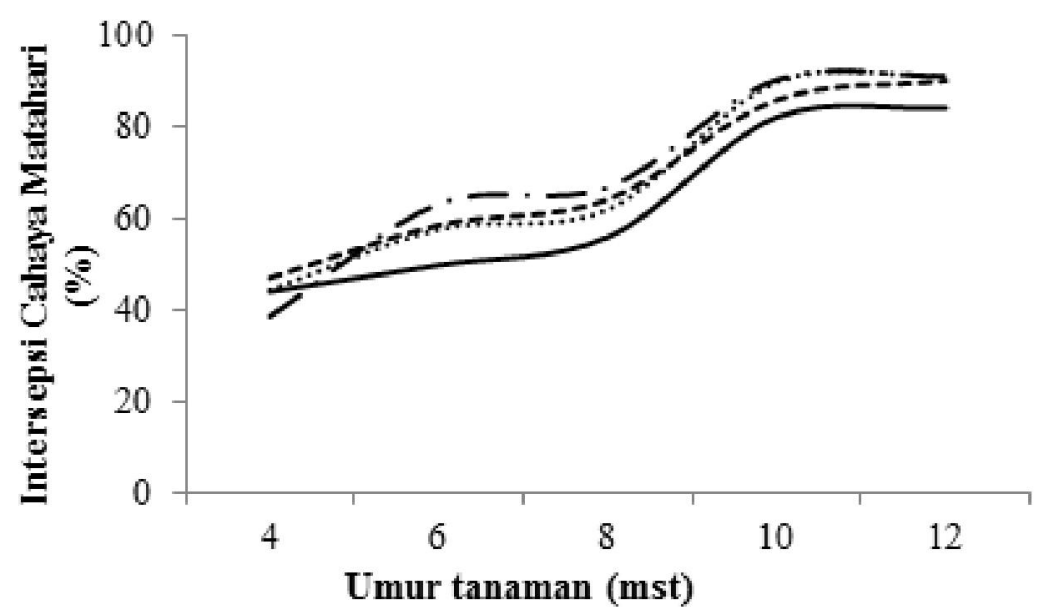

Gambar 2. Pola intersepsi cahaya matahari tanaman sorgum pada berbagai kerapatan tanaman. $-=1$ tanaman per lubang; $--=2$ tanaman per lubang; $\cdots \cdots=3$ tanaman per lubang; $-\cdots=4$ tanaman per lubang

dengan kerapatan satu tanaman per lubang tanam. Pada kerapatan tinggi, hanya daun teratas yang mampu secara optimal menyerap cahaya matahari, sedangkan daun bagian bawah ternaungi oleh daun-daun yang berada di atasnya.

Secara umum persentase intersepsi cahaya nyata berkorelasi negatif dengan hasil tanaman sorgum (Tabel 4). Hal ini menunjukkan persentase intersepsi cahaya matahari berpengaruh terhadap laju fotosintesis tanaman. Pada varietas Numbu, semakin tinggi persentase intersepsi cahaya matahari akan menurunkan bobot biji per malai tanaman sorgum. Pada varietas Keller, Peningkatan persentase intersepsi cahaya matahari akan menurunkan jumlah biji per malai, bobot biji permalai, bobot biji per $\mathrm{m}^{2}$, bobot 100 butir, dan bobot brangakasan kering. Hal ini dikarenakan rendahnya persentase cahaya yang diperoleh tiap individu tanaman sorgum akibat persaingan antar tanaman, sehingga menurunkan hasil tanaman sorgum. Pada kerapatan yang tinggi, energi yang sama terbagi ke lebih banyak tanaman per lubang tanam. Sesuai dengan pendapat Kroppf dan Lotz (1993) dalam Suwarto dkk. (2005), penurunan hasil tanaman dapat terjadi karena adanya persaingan antar spesies tanaman dalam mendapatkan faktor tumbuh.

Rekomendasi dari hasi penelitian ini adalah penggunaan varietas Numbu dengan kerapatan tanaman dua tanaman per lubang. Varietas Numbu dengan kerapatan dua tanaman per lubang menghasilkan intersepsi cahaya matahari tertinggi dibandingkan dengan varietas Keller dan Wray pada kerapatan yang sama. Apabila ditanam lebih dari dua tanaman per lubang, kemungkinan menyebabkan penurunan hasil tanaman sorgum.

\section{KESIMPULAN}

Berdasarkan hasil dan pembahasan yang telah diuraikan maka dapat diambil kesimpulan bahwa: (1) Kerapatan tanaman berpengaruh nyata terhadap pola intersepsi cahaya matahari tanaman sorgum. Secara umum kerapatan empat tanaman perlubang tanam memiliki pesentase intersepsi cahaya matahari tertinggi. (2) Intersepsi cahaya matahari ketiga varietas sorgum menunjukkan pola yang relatif sama pada berbagai umur tanaman. (3) Interaksi antara varietas dengan kerapatan tanaman berpengaruh nyata terhadap intersepsi cahaya matahari tanaman sorgum pada tumpangsari dengan ubikayu pada umur 5 dan 7 mst. (4) Persentase intersepsi cahaya matahari tanaman sorgum nyata berkorelasi negatif dengan jumlah biji per malai, bobot biji per malai, bobot biji per $\mathrm{m}^{2}$, bobot 100 butir, dan bobot brangkasan kering.

\section{DAFTAR PUSTAKA}

Gardner, F.P., R.B. Pearce, and R.L. Mitchell. Diterjemahkan oleh Susilo, H. dan Subiyanto. 1991.Fisiologi Tanaman Budidaya. Penerbit Universitas Indonesia (UI press). Jakarta. 428 hal.

Hamim, H., R. Larasati dan M. Kamal. 2012. Analisis komponen hasil sorgum yang ditanam tumpangsari dengan ubi kayu dan waktu tanam berbeda. Prosiding Simposium dan Seminar Bersama PERAGI-PERHORTIPERIPIHIGI Mendukung Kedaulatan Pangan dan Energi yang Berkelanjutan. p 91-94. Bogor, 1-2 Mei 2012. 
Tabel 4. Korelasi persentase intersepsi cahaya matahari pada umur tanaman berbeda dengan komponen hasil beberapa varietas sorgum.

\begin{tabular}{|c|c|c|c|c|c|c|c|}
\hline $\begin{array}{l}\text { Intersepsi } \\
\text { cahaya }\end{array}$ & $\begin{array}{c}\text { Umur } \\
\text { tanaman }\end{array}$ & $\mathrm{JB}$ & $\mathrm{BB}$ & $\mathrm{BBM}$ & BSB & $\mathrm{BBB}$ & B BK \\
\hline \multirow{8}{*}{ Numbu } & 4 & $-0,079^{\text {tn }}$ & $-0,413^{\mathrm{tn}}$ & $0,422^{\text {tn }}$ & $-0,362^{\mathrm{tn}}$ & $-0,118^{\mathrm{tn}}$ & $0,174^{\text {tn }}$ \\
\hline & P-value & 0,808 & 0,182 & 0,172 & 0,248 & 0,716 & 0,590 \\
\hline & \multirow[t]{2}{*}{6} & $-0,107^{\mathrm{tn}}$ & $-0,593 *$ & $0,361^{\text {th }}$ & $-0,082^{\mathrm{tn}}$ & $-0,041^{\mathrm{tn}}$ & $0,326^{\text {tn }}$ \\
\hline & & 0,740 & 0,042 & 0,250 & 0,801 & 0,900 & 0,302 \\
\hline & \multirow[t]{2}{*}{8} & $-0,313^{\mathrm{tn}}$ & $-0,657 *$ & $0,412^{\text {th }}$ & $-0,228^{\text {tn }}$ & $-0,229^{\mathrm{tn}}$ & $0,101^{\text {tn }}$ \\
\hline & & 0,321 & 0,020 & 0,184 & 0,476 & 0,475 & 0,755 \\
\hline & \multirow[t]{2}{*}{10} & $-0,525^{\mathrm{tn}}$ & $-0,749 *$ & $0,505^{\text {tn }}$ & $-0,563^{\mathrm{tn}}$ & $-0,442^{\text {tn }}$ & $0,091^{\text {tn }}$ \\
\hline & & 0,08 & 0,005 & 0,094 & 0,057 & 0,150 & 0,778 \\
\hline \multirow{8}{*}{ Keller } & 4 & $-0,506^{\mathrm{tn}}$ & $-0,525^{\mathrm{tn}}$ & $-0,614 *$ & $-0,605 *$ & $-0,322^{\mathrm{tn}}$ & $-0,441^{\text {tn }}$ \\
\hline & P-value & 0,093 & 0,079 & 0,034 & 0,037 & 0,307 & 0,152 \\
\hline & \multirow[t]{2}{*}{6} & $-0,228^{\mathrm{tn}}$ & $-0,294^{\mathrm{tn}}$ & $0,247^{\text {tn }}$ & $-0,192^{t n}$ & $-0,182^{\text {tn }}$ & $-0,145^{\text {tn }}$ \\
\hline & & 0,476 & 0,354 & 0,439 & 0,549 & 0,571 & 0,654 \\
\hline & \multirow[t]{2}{*}{8} & $-0,466^{\mathrm{tn}}$ & $-0,502^{\mathrm{tn}}$ & $0,192^{\text {th }}$ & $-0,146^{\mathrm{tn}}$ & $-0,523^{\text {tn }}$ & $-0,582 *$ \\
\hline & & 0,127 & 0,096 & 0,549 & 0,651 & 0,081 & 0,047 \\
\hline & \multirow[t]{2}{*}{10} & $-0,606 *$ & $-0,661 *$ & $-0,104^{\text {tn }}$ & $-0,503^{\text {tn }}$ & $-0,370^{\text {tn }}$ & $-0,371^{\mathrm{tn}}$ \\
\hline & & 0,0369 & 0,019 & 0,747 & 0,096 & 0,237 & 0,235 \\
\hline \multirow{8}{*}{ Wray } & 4 & $-0,228^{\mathrm{tn}}$ & $-0,258^{\mathrm{tn}}$ & $-0,087^{\mathrm{tn}}$ & $-0,090^{\mathrm{tn}}$ & $-0,222^{\text {tn }}$ & $-0,230^{\text {tn }}$ \\
\hline & P-value & 0,476 & 0,418 & 0,787 & 0,781 & 0,489 & 0,473 \\
\hline & \multirow[t]{2}{*}{6} & $0,367^{\text {tn }}$ & $0,275^{\text {tn }}$ & $0,369^{\text {m }}$ & $0,023^{\text {tn }}$ & $0,198^{\mathrm{tn}}$ & $0,126^{\text {tn }}$ \\
\hline & & 0,241 & 0,387 & 0,238 & 0,944 & 0,537 & 0,697 \\
\hline & \multirow[t]{2}{*}{8} & $0,169^{\text {tn }}$ & $0,046^{\text {tn }}$ & $-0,223^{\text {tn }}$ & $-0,267^{\mathrm{tn}}$ & $0,496^{\text {tn }}$ & $0,413^{\text {tn }}$ \\
\hline & & 0,599 & 0,888 & 0,487 & 0,402 & 0,101 & 0,182 \\
\hline & \multirow[t]{2}{*}{10} & $0,316^{\mathrm{tn}}$ & $0,235^{\text {tn }}$ & $0,539^{\text {tn }}$ & $0,141^{\mathrm{tn}}$ & $0,042^{\text {tn }}$ & $-0,056^{\mathrm{tn}}$ \\
\hline & & 0,317 & 0,462 & 0,071 & 0,662 & 0,897 & 0,863 \\
\hline
\end{tabular}

Keterangan: JB (Jumlah biji per malai), BB (Bobot biji per malai), BBM (Bobot biji per m²), BSB (Bobot 100 butir), BBB (Bobot brangkasan basah), BBK (Bobot brangkasan kering), tn = tidak nyata pada taraf $5 \%$, dan $*=$ nyata pada taraf $5 \%$. 
Kantur, D., Dj. Prajitno, dan P. Yudono. 2006. Kajian defoliasi sorgum pada tumpangsari dengan kacang hijau. Politeknik Pertanian Negeri Kupang. Fakultas Pertanian Universitas Gajah Mada. Yogyakarta.Hal: $57-65$.

Lesoing, 1995. and Ch.A. Francis, 2000. Strip intercropping effects on yield and yield components of corn, grain sorghum, and soybean. AgronJ. 91: 422-426.

Pembengo, W., Handoko, dan Suwarto. 2012. Efisiensi penggunaan cahaya matahari oleh tebu pada berbagai tingkat pemupukan nitrogen dan fosfor. $J$. Agron. Indonesia 40(3): 211 -217.

Sari, L.W., N. Nugrahaeni, Kuswanto, dan N. Basuki. 2013. Interakasi genotipe $\mathrm{x}$ lingkungan galur-galur harapan kedelai (Glycine max (L)).Jurnal Produksi Tanaman 1(5): 436.

Sirappa, M.P. 2003. Prospek pembangunan sorgum di Indonesia sebagai komoditas alternatif untuk pangan, pakan, dan industri.Jurnal Penelitian dan Pengembangan Pertanian 22(4): 133-140.
Suryadi, L. Setyobudi, dan R. Soeliytyono. 2013. Kajian intersepsi cahaya matahari pada kacang tanah ( Arachis hypogeae L.) diantara tanaman melinjo menggunakan jarak tanam berbeda. Jurnal Produksi Tanaman 1(4): 49.

Suwarto, S., Y. Handoko dan M. A. Chozin. 2005. Kompetisi tanaman jagung dan ubikayu dalam sistem tumpangsari.Jurnal Agronomi 2(33): 17.

Talanca, A.H. 2011. Status sorgum sebagai bahan baku bioetanol. Seminar nasional 3-4 Oktober 2011. Balai Penelitian Tanaman Serelia. Hal: 556560.

Warsana. 2009. Introduksi Teknologi Tumpangsari Jagung dan Kacang Tanah. Dimuat dalam Tabloid Sinar Tani, 25 Februari 2009. BPTP Jawa Tengah. 